\title{
ASSOCIATIVISMOS DE EXTREMA DIREITA NA ERA PÓS 11 DE SETEMBRO
}

\author{
Ana Paula Tostes ${ }^{1}$
}

\begin{abstract}
Resumo
Um mapeamento mais preciso das ações de "grupos de ódio", bem como a sua repressão, passou a ser incluído no tratamento estratégico de atos de terrorismo e de ameaça à segurança nos Estados Unidos nas últimas décadas, na mesma tendência do ocorrido em países europeus em função do crescimento da extrema direita e da xenofobia. Dois marcos cronológicos são fundamentais para compreender mudanças significativas na postura de autoridades norte americanas sobre a ação de "grupos de ódio", sejam eles supremacistas ou milicianos: os atentados de 11 de setembro de 2001 e a eleição de Obama em 2008. Este artigo procura contribuir para o entendimento, tanto da mudança de concepção de "terrorismo", quanto da identificação de efeitos desta mudança refletidos em novos enquadramentos de crimes de ódio e na classificação e mapeamento das ações de grupos extremistas norte americanos de direita.
\end{abstract}

Palavras-chave: Extrema direita. Intolerância. 11 de setembro. Supremacia branca. Xenofobia.

\section{Far Right associations IN POST SEPTEMBer 11 ERA}

\section{Abstract}

A more precise mapping of the actions of «hate groups» as well as its repression, were included in the strategic treatment of acts of terrorism and security threat in the United States in recent decades. The same trend has occurred in European countries due to the growth of extreme right and xenophobia. Two chronological milestones

\footnotetext{
${ }^{1}$ Docente do Departamento de Ciências Sociais e Programa de Pós Graduação de Relações Internacionais - Universidade Estadual de Rio de Janeiro, Brasil. aptostes@uerj.br
} 
are key to understanding significant changes and a new approach of U.S. authorities concerning the action of «hate groups», whether supremacists or the militia: the attacks of September 11, 2001, and the election of Obama in 2008. This article seeks to contribute to the understanding of both the change in the concept of «terrorism», and the identification of the effects of this change reflected in new guidelines for hate crimes as well as the classification and mapping of the actions of extremist right-wing American groups.

Keywords: Far-right. Intolerance. September 11. White supremacy. Xenophobia.

"Há uma guerra de raças contra brancos. No entanto, nosso povo minhas irmãs e irmãos brancos - estarão compromissados com uma solução não violenta. Esta decisão deve consistir em solidariedade entre comunidades brancas pelo mundo. 0 ódio pelas nossas crianças e seu futuro está crescendo e sendo alimentado a cada dia. Estejam firmes nas suas conviç̧ões. Mantenbam-se amando sua berança e testemunbando a outros de que bá um caminho melhor do que o de uma guerra rasgada e uma ordem mundial socialista, violenta e perversa. Esse caminho é o caminho cristão - lei e ordem - amor à familia - amor à nação. Estes são os princípios da civilização ocidental. Existe uma guerra para se destruir tais coisas. Rezem para que nosso povo veja os erros desses caminhos e retomem o senso de lealdade. Arrependa-se America! Sejam fiéis meus caros."

Pastor Thomas Robb², Diretor Nacional do "The Knights Party"

\section{INTRODUÇ̃̃o}

discurso fundamentalista cristão norte americano, pela lei e ordem, pela defesa de instituições e valores tradicionais como família e nação, embora seja aparentemente contra o uso da força, suscita emoções e atitudes radicais e o radicalismo culmina, com freqüência, na violência. 0 "caminho cristão" fundamentalista refletido no exemplo do fragmento do discurso acima, amplamente divulgado pela mídia digital desde 2008, foi pronunciado pelo pastor Thomas Robb, atual diretor nacional do "The Knights Party", que sucedeu

\footnotetext{
${ }^{2}$ Texto traduzido do inglês livremente pela autora. Cf. www.kkk.com
} 
o polêmico David Duke. ${ }^{3}$ Nas palavras desse líder extremista vimos o apelo da importância da identidade.

Este artigo não trata da relação entre identidade e política, porém se insere no amplo leque de debates sobre o tema, na medida em que os valores e tendências dos extremismos de direita, sejam norte americanos, sejam europeus, bem como crimes praticados por "grupos de ódio", que se organizam em defesa de ideias radicais sobre intolerância racial, religiosa e/ou cultural, ou ainda, comportamento sexual - relacionam seus ideais e atitudes à defesa de uma pressuposta identidade ameaçada. Muitas vezes a diferenciação de nuances nos discursos de extrema direita, variados tanto nos Estados Unidos (EUA), quanto na Europa, é difícil de ser decifrada. Um exemplo emblemático é o que aconteceu na ocasião da campanha eleitoral norte americana para presidente em 2008.

Muitos jornais divulgaram nos EUA o apoio da Ku-Klux-Kan (KKK), grupo mais preponderante e representativo do extremismo americano, à candidatura de Obama e, como consequência, algumas conclusões precipitadas levaram a considerar que a recente renovação do grupo extremista KKK, teria se revelado por uma postura política mais flexível e tolerante. Cenário aparentemente confuso e contraditório, que rapidamente se esclareceu com as assumidas declarações de membros da KKK sobre uma exaltada rejeição por Hillary Clinton; algo mais forte do que a eventual inconveniência em ter-se Obama como presidente. A fúria anunciada e veiculada, principalmente pela internet, nas palavras de um dos atuais líderes mais populares do Knights' Party, o "Imperial Wizard of the Knights Party" - como é chamado Ronald Edwards - assim se revelara em uma declaração sua em que dizia que "qualquer um ou qualquer coisa" poderia ser melhor do que a "louca (sic!)" ("crazy $a^{* * *} b^{* * * * *), ~ r e f e r i n d o-s e ~ a ~ H i l l a r y ~ C l i n t o n . ~}$

Sob um claro cenário de dupla insatisfação, lideranças da KKK se viram tendo que escolher entre a defesa de idéias consideradas feministas e socialistas de Clinton ou uma promessa democrata sem exploração do perfil racial por parte de Obama. ${ }^{5}$ Assim, embora jamais confirmado pelos democratas, o eventual suporte financeiro ou moral dado pela KKK à campanha de Obama suscita uma necessária

\footnotetext{
${ }^{3}$ David Duke foi um dos líderes mais importantes e conhecidos da história recente da KKK.

4 "Grupos de ódio" ou "hate groups", são considerados aqueles que compartilham hostilidades geralmente referentes à raça e/ou outros aspectos de identidade, seja gênero, religião, etnia, nacionalidade ou orientação sexual.

${ }^{5}$ A marcante rejeição a Hillary por extremistas de direita se dá principalmente em função de sua atuação na reforma do sistema de saúde americano na ocasião do governo de Bill Clinton.
} 
reflexão sobre o que significa, o quanto são poderosos e o que defendem os "grupos de ódio". Em especial, este artigo explora o caso dos movimentos "supremacistas brancos" americanos, conhecidos pela defesa de ideais e opiniões radicais ultra conservadoras, que agem livremente em defesa de valores incompatíveis com 0 pluralismo democrático, tais como a segregação social, hierarquização racial e intolerância religiosa.

Este artigo é fruto parcial de uma pesquisa sobre ultra conservadorismo e procura contribuir para a reflexão sobre indícios do aumento do radicalismo de direita nos EUA, a partir de dois marcos cronológicos: os atentados de 11 de setembro de 2001 e a eleição de Obama em 2008. Estes eventos afetaram tanto 0 crescimento dos movimentos extremistas nos EUA por um lado, como geraram um aumento da atenção das autoridades norte americanas de inteligência e segurança nas ameaças promovidas por estes grupos, por outro lado. Com mais ênfase do que na década anterior, a partir de 2001, "grupos de ódio" passam a ser incluídos como movimentos que ameaçam a segurança, seus atos violentos e crimes categorizados como terroristas e, como consequência, seu monitoramento passa a ser considerado uma prioridade nos EUA, como já acontecia na Europa. 0 extremismo de direita na Europa tem sido ostensivamente estudado, em contraste ao caso americano. Assim, este artigo busca ainda colaborar para a identificação de zonas de contato e de diferenciação entre tendências do extremismos de direita norte americano e europeu.

\section{O QUE HÁ DE NOVO NA EXTREMA DIREITA?}

$\mathrm{Na}$ Europa, a novidade do radicalismo de direita está baseada, essencialmente, na mudança da sociedade industrial em sociedade pós-industrial (IGNAZI; PERRINEAU, 2000). Ou seja, transformações econômicas e sociais estruturais teriam gerado o aparecimento ou recrudescimento de reivindicações identitárias e culturais típicas de desafios sociais contemporâneos. 0 novo movimento de extrema direita (far right movement), que se molda desde a década de 1970, organiza-se na década de 1980, tanto na Europa quanto nos EUA, e se fortalece na década de 1990, é diagnosticado por Ignazi (1996) como um

\footnotetext{
6 "Supremacia branca" é uma expressão da crença de que os brancos são superiores aos povos de outras origens raciais. Como consequência, o termo é frequentemente utilizado para descrever uma ideologia política que defende a dominação social e política pelos brancos e promove a crença supremacista através de diferentes meios e formas de associação.
} 
produto das mudanças sociais que revela novos tipos de intolerância do tipo ultranacionalista, supremacista e anti-imigração.

Vários estudos, fragmentadamente, têm refletido uma crescente preocupação sobre 0 aumento desta forma de se pregar a segregação social na Europa, muitas vezes invisível aos olhos da política norte americana organizada e partidarizada. Autores como Berlete Lyons (2000), Hainsworth, (1992) e Hofstadter (1996) contribuíram com análises importantes sobre o extremismo de direita nos EUA, mas a literatura sobre o tema ainda é escassa. Paralelamente a um relativo desinteresse acadêmico sobre o tema vimos, an longo da pesquisa que gerou este artigo que, nas últimas décadas, "grupos de ódio" mais antigos e tradicionais vêm se remodelando e outros vêm surgindo com diferentes nuances, diferentes graus de xenofobia, homofobia, racismos e uso da violência, mas que compartilham valores e atitudes ultraconservadoras em relação à integração multicultural e às consequências das transformações da sociedade americana (DIAMOND, 1995).

Os grupos supremacistas americanos passaram por diferentes momentos de desenvolvimento e variam quanto ao conteúdo de suas plataformas, mas contemporaneamente estes se formam em torno da busca da ordem e da recuperação e construção de uma identidade, uma ética e mesmo uma origem racial que é vista como ameaçada, ferida ou decaída. Com isso, assistimos desses grupos uma rejeição aberta e amplamente divulgada, principalmente por meios digitais, à predominância de valores do liberalismo político, pluralismo cultural, equidade e tolerância étnica, racial e religiosa.

Enquanto nos EUA os agrupamentos xenófobos não vinham sendo temidos como na Europa, após os eventos de 11/09 as coisas começaram a mudar. 0 FBI e outros departamentos do governo dos EUA passaram a investigar, classificar e produzir alguma inteligência sobre a atuação, os alvos e os números relativos ao extremismo americano como nunca antes. Momento crucial para esta mudança de tratamento é identificado a partir dos ataques terroristas de 11/09, com a publicação do "Ato Patriota."” No "Ato Patriota", o termo terrorismo foi expandido e a definição de "atividades terroristas" foi oficialmente alterada, passando a incluir quaisquer ações envolvendo o uso de meios perigosos de ameaça a vida

\footnotetext{
${ }^{7}$ Um conjunto de medidas de contraterrorismo, aprovadas pelo Congresso norte Americano, estabelecido pelo governo do Presidente George W. Bush em 26 de outubro, logo após os atentados terroristas de 11 de setembro de 2001. 0 ato visou "unir e fortalecer o governo para prover ferramentas apropriadas para interceptar e obstruir o terrorismo" Cf. http://w2.eff.org/ patriot/20020925_patriot_act.php.
} 
(não apenas explosivos ou armas de fogo). No mesmo documento, "engajamento em atividades terroristas" passou a ser definido como qualquer ato de incitação, planejamento, participação ou cometimento na preparação de "ato considerado terrorista," assim como o termo "terrorismo" passa então a abarcar tanto ameaças internacionais como domésticas. "Atos de anarquismo extremista" é como passam a ser enquadradas ações de ameaça à segurança doméstica, incluindo-se aquelas cometidas por extremistas de direita ou "grupos de ódio" de qualquer natureza antes considerados crimes comuns.

Com o desejo e a necessidade de uma segurança mais rigorosa, além de se ter atribuído maior poder às agências americanas para rastrear e mapear grupos e organizações extremistas - agora comparados a organizações terroristas - foram estabelecidos novos termos e limites para o uso de forças de segurança e polícia investigativa e repressiva para ações criminosas domésticas de ameaça à segurança. Neste contexto, atos de grupos extremistas de direita passam a receber também um tratamento especial por autoridades como o FBI, não apenas pelo conteúdo de suas ideologias, mas pela tênue linha entre a intolerância de grupos milicianos e fundamentalistas e terrorismos de qualquer espécie. Como consequência, o FBI passa a designar como "extremismo anarquista" atos de violência e/ou desobediência às leis e desrespeito a liberdades civis, disfarçados em ideologias que defendem a autonomia da sociedade para resolver, com as "próprias mãos" e com o uso da violência, o que se acredita que o sistema político não estaria resolvendo satisfatoriamente (FBI, 2007, p. 18-20, 2009).

Em relatório do FBI de 2008, em que se classificaram 203 indivíduos extremistas identificados, presos ou mortos, no período de 11 de setembro de 2001 até maio de 2008, os pertencentes a grupos supremacistas brancos se destacam. Mesmo quando ocorre uma afiliação múltipla, dentre os grupos radicais extremistas, aqueles que se destacam pela ideologia supremacista branca são proeminentes (FBI, 2008b).

Os dados do FBI ainda revelam que os supremacistas têm uma ampla experiência militar, o que indica uma comunhão de ideias extremistas com práticas de ação que poderiam culminar em violência e real ameaça à ordem estabelecida. Os skinheads foram identificados como o grupo supremacista com componentes mais jovens e mais violentos que agregam membros com experiência militar para treinamentos milicianos. 0 alvo da violência dos skinheads foi também mapeado pelo FBI, revelando que cerca de 54\% dos atos violentos investigados e cometidos por skinheads, de janeiro de 2007 a meados de 2008, foram direcionados a grupos 
étnicos e outras minorias, incluindo hispânicos, asiáticos, árabes e homens homossexuais (FBI, 2008a). Este foi um período importante de campanha para as eleições e preparação de debates nos quais Obama começa aparecer como símbolo de transformação e esperança de diversidade e representatividade racial, embora não tenha procurado explorar este aspecto em sua campanha.

Além do FBI, inúmeros institutos de pesquisa também passam a mapear ações de grupos extremistas americanos. 0 centro de estudos sobre terrorismo, 0 National Consortium for the Study of Terrorism and Responses to Terrorism $(\text { START })^{8}$, disponibiliza dados atualizados sobre terrorismo nos EUA e no mundo. Dentre os bancos de dados "open-source" disponibilizados, o Global Terrorism Database (GTD) reúne informações sobre mais de 98.000 eventos terroristas ao redor do mundo de 1970 a 2010, sendo atualmente um dos bancos de dados mais abrangentes sobre eventos terroristas no mundo, pois sobre cada incidente classificado no GTD encontram-se detalhes sobre a data e o local, armas utilizadas, a natureza do alvo e o número de vítimas.

Utilizando-se deste banco de dados, uma equipe de pesquisadores reuniu algumas informações conclusivas sobre o caso americano publicadas no START (2010). Dentre elas se destaca que entre 1990 e 2010, a cada 345 homicídios, pelo menos um foi cometido por um ativista de extrema direita e milicianos. A distinção entre grupos supremacistas e organizações milicianas nem sempre é clara e nem sempre eles agem isoladamente, no entanto é importante perceber que esses grupos possuem características diferentes. Milicianos são grupos paramilitares que se organizam principalmente a partir da década de 1990 nos EUA. Inspirados nos ideais da Independência pregam discursos sobre "liberdade individual na luta contra o Estado." Geralmente são formados por americanos jovens e/ou veteranos de guerra que possuem experiência no manuseio de armas e defendem o porte de armas nos EUA "como garantia da expressão individual, contra a qual o Estado conspiraria" (MEDEIROS, 2007).

Os alvos das milícias são prioritariamente oficiais de governo ou defensores e/ou representantes da lei e do Estado (Law enforcement officials), tais como policiais, militares, advogados, juízes, etc. 0 aumento das milícias se tornou uma preocupação e a repressão de suas ações um desafio para a inteligência americana atualmente. Embora, como está ilustrado anteriormente, outros grupos

${ }^{8}$ Centro de excelência do U.S. Department of Homeland Security, baseado na Universidade de Maryland, Cf. http://www.start.umd.edu/start/announcements/announcement.asp?id=185. 
também apresentem forte componente de experiência militar, os milicianos são deliberadamente portadores de armas e privilegiam a formação e o treinamento paramilitar.

Outra fonte importante sobre a ação dos "grupos de ódio" é o Southern Poverety Law Center (SPLC) ${ }^{9}$ que também tem monitorado os crimes de ódio. Alguns resultados recentemente divulgados demonstram o aumento destes crimes em cerca de 54\% entre 2000 e 2007 e de 4\% considerando-se o período entre 2007 e 2008. A ideia de se ter um "Homem negro na Casa Branca, combinado com o aprofundamento da crise econômica e a persistência de elevados níveis de imigração latina, deu aos supremacistas brancos uma verdadeira plataforma sobre a qual recrutar novos simpatizantes." 10

Quando a economia sofre, pessoas procuram soluções e culpados, e neste contexto, um resultado dramático foi o crescimento de afiliações em grupos de extrema direita nos EUA nos moldes do aumento de ativismos e partidos políticos de extrema direita, também observados na Europa (IGNAZI, 2003; MUDE, 2007; NORRIS, 2005). A própria EUROPOL identificou a relação entre o crescimento da capacidade de persuasão de discursos de extrema direita e a crise econômica, em relatório de 2011 (TE-SAT, 2011).

Guardadas as devidas diferenças, é preciso reconhecer que extremismos são similares tanto na natureza de seus valores quanto nas suas atuais estratégias de ação, que se utilizam da internet e interações transnacionais, associações virtuais e suporte financeiro e moral remoto. Desemprego e atitudes céticas quanto às instituições e aos políticos - é fundamentalmente do que se alimentam os discursos e a propaganda, tanto de extrema direita na Europa, quanto nos EUA. Ambos têm como alvo de crítica as transformações das sociedades contemporâneas em espaços de inclusão de minorias, atitudes e preferências sexuais e sociais não tradicionais, não religiosas ou culturalmente diferentes - o que efetivamente ocorre com o aumento da imigração.

\footnotetext{
${ }^{9}$ A Southern Poverety Law Center é uma Organização não-governamental sem fins lucrativos fundada por movimentos de direitos civis em 1971 e constituída por advogados e importantes programas de proteção de direitos civis, contra hate and bigotry, e especialmente monitora 0 racismo institucional e grupos supremacistas brancos. Cf. http://www.splcenter.org/.

${ }^{10}$ Traduzido livremente pelo autor. Cf. The Leadership Conference. The Nation's premier civil \& human rights coalition. Cf. http://www.civilrights.org/publications/hatecrimes/white-supremacist. html.
} 


\section{Networks DE ÓDIo?}

Segundo Castells (2004), o conceito de network society sugere uma mudança fundamental ocorrida no seio da organização das sociedades. Castells enfatiza a fluidez do poder através da circulação de ideias, valores e informação, além do capital e bens, como sendo precedente e possivelmente mais influente do que a circulação do poder através das relações de classe e instituições governamentais - que teria caracterizado as sociedades industriais. Segundo a tese do autor, uma sociedade "pós-industrial" atribui poder a grupos que se articulam em espaços não institucionais, não oficiais e não partidários. 0 que exige uma perspectiva nova, complexa e multidimensional ("multi-level" e "multi-layered") para sua identificação e mapeamento (ANHEIER; KATZ, 2003, p. 241). Este pode ser considerado o mesmo contexto de análise que teria levado Robert Putnam (2000) a uma autocrítica sobre a necessária relação entre associativismos voluntários e a constituição de virtudes cívicas que asfaltam a democracia.

Em outras palavras, a capacidade de associação não gera necessariamente benefícios sociais e públicos, pois esta pode se dar para a articulação de interesses opostos à agregação e à coesão social. Associações voluntárias também servem como microcosmos de intolerância e resistência ao pluralismo por aqueles já designados por Beck como ugly citizens (BECK apud KALDOR, GLASIUS, 2002). Além disso, o aumento de tecnologias de informação e organização social em rede tem facilitado a articulação não apenas nacional, mas também transnacional de idéias xenófobas e interação entre grupos com interesses comuns repudiados em uma sociedade aberta, em que reinem valores democráticos e todos são respeitados nas suas diferenças e preferências.

0 caráter internacional e transnacional da xenofobia parece contraditório, pois a estratégia de organização e construção de networks internacionais de grupos racistas que pregam a supremacia cultural e de raças, que incitam ódio e segregação, é a de utilizar-se do direito à associação, da liberdade de expressão e opinião, para divulgar idéias sobre intolerância. Sendo assim, o que se tem verificado é que a garantia constitucional de todas as manifestações de idéias e valores, desde que respeitados os atuais direitos protegidos pelas instituições, segundo o espírito da primeira emenda constitucional, tem permitido a divulgação e organização da extrema direita nos EUA como em poucos países europeus.

Apenas para ilustrar, o SPLC classificou em 2010 cerca de 1.002 "grupos de ódio" ativos nos EUA, tendo considerado apenas organizações com sedes 
conhecidas. Esta identificação foi possível apenas através da internet, websites e publicações on line, além de informações e apreensões de material sobre atividades consideradas criminosas que revelam redes transnacionais de organização (SOUTHERN POVERTY LAW CENTER, 2011). Grupos de diversas organizações de extrema direita não partidárias cooperam entre si e se articulam com grupos de outros países através da internet e de redes sociais. As formas de organização e causas de intolerâncias são variadas, mas movimentos neo nazistas como 0 Nações Arianas, Aliança Nacional (que também agem na Europa) ou a KKK, por exemplo, misturam valores do nazismo e do cristianismo fundamentalista e agem nos EUA e na Europa de forma articulada, inclusive recrutando membros e simpatizantes de diferentes países.

Após a eleição de Obama, as atividades on line de grupos supremacistas aumentaram notadamente e novos fóruns on line de ideias racistas e xenófobas foram identificados pelas agências de pesquisa citadas. Don Black, ex Grand Wizard da KKK, afirmou que mais de 2.000 pessoas acessaram o website da KKK no dia da eleição de Obama, quando a média de acessos por dia era de 80 pessoas. A KKK alega ter aumentado seus membros, chegando a cerca de 110.000 desde o período da pré candidatura de Obama e de Bill Clinton, e que este cenário teria sido um importante catalisador do sucesso de seu crescimento recente. Pela via da internet, um aumento significante de acessos e busca de filiações foram identificados neste período e muitos acessos foram feitos por pessoas que, pela primeira vez, buscaram grupos extremistas para avaliar sua eventual simpatia, muitos inclusive passando a interagir com membros ou tornando-se membros e afiliados (CHEN, 2009).

\section{Pontos de contato entre eXtremismos}

$\mathrm{Na}$ Europa, partidos de extrema direita possuem fortes relações com grupos ativistas racistas não partidários, pois muitos de seus líderes partidários são oriundos destes grupos. Apenas para exemplificar, no caso da Espanha podemos citar 0 Movimiento Social Republicano (MSR), criado em 2000, que tem compromissos com a Alternativa Europea, Resistencia e a Red Vértice - que são "grupos de ódio" formados por intolerantes de várias espécies: participam destes grupos racistas, xenófobos e homófobos. Existem outros partidos fascistas tradicionais como a Falange Española que mantém relações com grupos de ativistas de direita como a Nación Joven, a Juventud e Patria Libre e a "associação dos ex- 
combatentes fascistas". á a Democracia Nacional (DN $)^{11}$ representa os valores do Partido Frente Nacional (FN) de Le Pen na Espanha. Seus líderes são ativistas de vários grupos, incluindo Nación Joven, Acción Radical, Vanguardia Nacional Revolucionária, Bases autónomas, Juntas Españolas e Círculo Español de Amigos de Europa (CEDADE).

Para entender a força da FN de Le Pen, criado como primeiro partido de extrema direita em 1972, e outros grupos ultraconservadores europeus que se renovam, principalmente a partir dos anos 1980, é preciso mencionar a inspiração nas idéias de Alain de Benoist, filósofo e jornalista francês fundador da Nouvelle Droite (nova direita). Benoist fundou a think-thank GRECE (sigla para "Grupo de Estudos e Pesquisas da Civilização Europeia” em francês) com o objetivo de dar um caráter mais intelectual a reivindicações de renovação de setores politicamente conservadores e assumidamente anti-americanistas, criticando o liberalismo de livre mercado e o igualitarismo. 0 multiculturalismo e a tolerância quanto à migração, acirrados nas décadas de 1970 e 1980 tanto nos EUA quanto na Europa, alimentaram as tendências extremistas e culminaram na organização da FN na França. A FN, no entanto, diferentemente das tendências originárias da GRECE, começara a apresentar um conteúdo religioso e católico tradicionalista. Logo, não seria adequando identificar uma acomodação total de ideias, mas mais apropriadamente, um diferente enfoque para as críticas extremistas e para posicionamentos em relação a políticas migratórias e ao racismo. Com a FN, ganham espaço temas ultraconservadores defendidos em discursos abertos de oposição ao aborto, à tolerância ao homossexualismo, e a cresce a simpatia pelo tema da pena de morte.

Le Pen foi militar e participou da guerra da Argélia entre 1954 e $1962^{12}$. Assim, para além de suas ideias, ele tem uma história de formação e experiência na interferência das políticas francesas colonizadoras e acompanhou as consequências da guerra: a cisão na sociedade francesa sobre a política externa da França em relação à Argélia, os radicalismos de esquerda que culminaram na primavera de 1968, bem como, a conseqüente transformação da sociedade francesa com a intensa imigração africana para a França no período pós guerra da Argélia. Mas, pode-se dizer que foi em 2002 que Le Pen e a FN passam a ser temidos por setores de centro e de esquerda na França, quando logo após os eventos

\footnotetext{
${ }^{11} \mathrm{~A}$ DN possui membros que exaltam Hitler e Franco.

${ }^{12}$ Le Pen foi identificado é acusado como torturador de guerra, mas na verdade ele conseguiu guardar a simpatia daqueles que se viram desagradados pelo desfecho da guerra.
} 
de 11/09, coincidentemente a França passava por uma crise política de seus líderes tradicionais representantes da ala conservadora e socialista, respectivamente Jacques Chirac e Lionel Jospin. Em um contexto de descrença e desinteresse político por parte dos franceses, vimos Le Pen alcançando o segundo turno das eleições presidenciais francesas e provocando um imenso espanto à sociedade internacional, principalmente, àqueles que acreditavam que a extrema direita deveria ser vista como uma ameaça menor, por não parecer ser forte o suficiente para alcançar poder institucional e governamental.

Na verdade, desde 2000 já havia sido criada uma importante network, a European Racism and Xenophobia Information Network (RAXEN), para servir como ferramenta central para a repressão ao racismo e à xenofobia na UE. Esta rede funciona para monitorar e divulgar informações e dados sobre a ocorrência de violência contra minorias religiosas, étnicas ou de imigrantes. Desde, pelo menos 2001, a mídia europeia já passava a estampar um importante alerta sobre 0 aumento da xenofobia na Europa e o crescimento da nova extrema direita. Em recente relatório da EUROPOL, o EU Terrorism Situation and Trend Report (TESAT, 2011), foram publicados dados sobre atividades terroristas e de extrema direita na região da UE, onde se destaca que as interações e a cooperação entre "these groups are becoming increasingly network-based". Ainda segundo o relatório, a cooperação e articulação entre grupos têm sido especialmente facilitadas pelo uso da internet e das redes sociais - o que tem permitido a profissionalização da produção de material extremista, bem como, a facilitação da coordenação e suporte a ações e campanhas. Em outras palavras, a internet tornou-se, nos últimos anos um crucial facilitador das ações tanto terroristas quanto extremistas (TE-SAT, 2011, p. 6).

0 terrorista de 22 de julho de 2011, que comandou o massacre do acampamento do Labour Party na ilha de Utoya, na Noruega, tinha uma atividade intensa de divulgação de suas idéias pela internet, tendo deixado vídeos gravados e emails com mensagens sublineares sobre suas opiniões e pretensões. No manifesto publicado livremente pela internet por Anders Breivik, encontram-se suas idéias extremistas representadas por ataques ao marxismo, ao multiculturalismo e à globalização. Isto implica concluir que sua atitude xenófoba e intolerante era pública e livremente divulgada, provavelmente com o objetivo de persuadir simpatizantes. Assim como em outros casos, é comum aos grupos de extrema direita se organizarem e propagarem suas posições intolerantes, articulando encontros e apoios políticos pela internet, como o caso já citado Knight's Party. 
A plataforma do Knights' Party sempre esteve amplamente divulgada na internet e dela consta a "defesa pelo reconhecimento da America como uma nação cristã e branca", que deve ter o direito de orgulhar-se de sua origem; o fim de qualquer ajuda internacional e abolição de todos os programas e políticas de ação afirmativa; o posicionamento das forças armadas nas fronteiras americanas e 0 fim da imigração. ${ }^{13}$

\section{Notas FinaIS}

Neste artigo foi dado destaque aos métodos e à capacidade de articulação dos "grupos de ódio", a distinção de suas características e plataformas, bem como a distinção e as afinidades entre grupos milicianos, que promovem a desobediência à ordem e às leis, e supremacistas, aqueles mais precisamente racistas e defensores de uma hierarquia racial branca. Tudo sem, no entanto, se procurar fazer uma crítica ao posicionamento governamental sobre o papel e o lugar de ativismos de extrema direita, mas identificando principalmente a mudança de tratamento dado ao problema das organizações milicianas e supremacistas, que passaram a integrar o foco de preocupação norte americana sobre o problema da segurança doméstica, notoriamente desde 2001.

0 estudo deste tema guarda uma certa necessidade de se considerar comparativamente atitudes xenófobas norte-americanas e europeias, sem que se deixe de considerar diferenças primordiais entre as duas regiões, suas sociedades e respectivas histórias. No caso dos EUA, esses guardam um orgulho civilizatório baseado na história da sua colonização, na origem cultural e religiosa dos primeiros imigrantes que fundaram o igualitarismo americano, na ética protestante e na crença nas instituições democráticas americanas. Desde a sua auto-imagem, o multiculturalismo e a constituição da "sociedade de imigração" norte americana (WALZER, 1997) se revelaria então como uma extensão dos preceitos democráticos e noções do Puritanismo colonial. Nada em contraste com a idéia de que a "América" seria uma terra "eleita por Deus" e os americanos capazes de se diferenciar historicamente pelos seus hábitos, costumes e crenças, aos moldes do que é identificado por Tocqueville, na Democracia na América, e é cultivado pela literatura colonial americana sobre a formação da ética e da cultura americanas.

Apesar da forte tradição de instituições representativas, que se alimentam

\footnotetext{
${ }^{13}$ www.kkk.com
} 
de um mito nacional puritano que justificaria um senso de "excepcionalismo", no reverso da moeda, a auto-imagem interpretada por uma vertente extremista ganhou uma outra versão por parte de grupos minoritários que vêem no multiculturalismo e na imigração a ameaça à supremacia branca e ao legado cultural dos fundadores da nação.

0 aumento da extrema direita, especificamente nos EUA, considerandose suas adaptações e modernizações nos discursos extremistas e supremacistas, já vinha sendo atribuído à resistência às transformações da sociedade americana crescentemente latina, mesmo antes dos eventos de 11 de setembro. Movimentos de liberalização social, erosão de hierarquias sociais que já sustentaram a sociedade tradicional americana, tais como raça e gênero, bem como o declínio da dominância americana internacional e novos problemas de segurança e expansão do Estado (BERLET; LYONS, 2000, p. 265), são consideradas algumas das causas do crescimento de adesões e da proliferação de grupos extremistas, bem como suas renovações.

No entanto, não apenas os estudos sobre este fenômeno, como também seu mapeamento, não ocupavam decisivamente espaço na mídia, nos centros de pesquisa e investigação, nem mesmo nas ações de monitoramento do próprio governo e instituições públicas. Diferentemente, na Europa, talvez como uma herança da experiência da Segunda Guerra Mundial, nunca se perdeu o foco e a atenção nos riscos da xenofobia e do crescimento da extrema direita, seja a partir de ativismos não partidários, seja pela via do aumento de votos em partidos de extrema direita - temas amplamente estudados na Europa (MUDE, 1996; TAGGART, 1996, 1998; KITSCHELT; McGANN, 1995; POGUNTKE; SCARROW, 1996; RYDGREN, 2004, 2007).

Além dos meios tradicionais, ativismos estruturados em networks transnacionais também ganharam um papel protagonista neste tema. Networks não se traduzem mais apenas como meios de cooperação na luta por direitos ou compartilhamento de valores que se traduziriam na produção do bem comum, pois seu papel instrumental serve também a interesses de ugly citizens que ameaçam a ordem e a segurança internas nos países. Como consequencia, o tema da segurança, antes orientado para ameaças territoriais, para a segurança do Estado ou restrito a debates no campo da diplomacia e das relações internacionais, passa a exigir uma complexidade maior em sua abordagem no âmbito da política doméstica. 
Nos EUA, os debates sobre terrorismo internacional e doméstico, seus riscos e estratégias de organização, passam a ser estudados desde uma perspectiva de estrutura e organização em redes transnacionais mais especificamente a partir dos ataques de 11/09 (KALDOR; GLASIUS, 2002; CASTELLS, 2004). Nesse contexto, forças policiais passaram a se organizar mais precisamente para enfrentarem 0 crescimento de um terrorismo de extrema-direita, alimentado por uma mistura de intolerância racial, xenofobia e certamente aprofundada pela onda anti-islâmica e profunda crise econômica que, tanto a Europa quanto os EUA, vem atravessando desde 2007-2008. Apenas para ilustrar, o Stormfront (2011), que é o maior website sobre o "poder branco" ("white-power") americano, operante desde 1995, obteve cerca de 42.700 acessos (por visitante) em outubro de 2008. Este aumento do interesse e curiosidade do cidadão médio americano pela ideologia supremacista vem sido atribuída a claro posicionamento ultra conservador sobre problemas como a imigração e a crise econômica (BELLO, 2008).

Enfim, podemos dizer que nos EUA hoje, como na Europa, os movimentos extremistas, que se alimentam das crises sociais e econômicas, já podem ser considerados parte de uma nova clivagem social intolerante e bastante ativa na divulgação e articulação de grupos que compartilham seus ideais e visões de mundo. Por outro lado, agências governamentais e políticas de ação contra 0 terrorismo já se adaptaram a este novo modelo de articulação e estratégias de ação em moldes sub-nacionais e transnacionais com consequências para seu monitoramento e repressão.

\section{REFERÊNCIAS}

ANHEIER, Helmut; KATZ, Hagai. Mapping global civil society In: GLASIUS, Marlies et al. (Ed.). Gobal civil society 2003. Oxford: Oxford University Press, 2003. p. 239-248.

BELLO, Marisol. White supremacists target middle America. USA Today, 21 Oct. 2008.

BERLET, Chip; LYONS, Matthew N. Right-wing Populism in America: too close for comfort. London: Guilford, 2000.

CASTELLS, Manuel. The crisis of democracy, global governance, and the rise of the global civil society. In: INTERNATIONAL SEMINAR FOR A GLOBAL GOVERNANCE, 2004, São Paulo. Anais... São Paulo: IFH- Instituto Fernando Henrique Cardoso, 2004. 
CHEN, Stephanie. Growing hate groups blame Obama, economy. 2009. Disponível em: <http://edition.cnn.com/2009/US/02/26/hate.groups.report/ index.html>. Acesso em: 1 set. 2011.

DIAMOND, Sara. Roads to dominion: right-wing movements and political power in the United States. London: Guilford, 1995.

FBI. Intelligence Assessment. A threat assessment for domestic terrorism. Washington:

Federal Bureau of Investigation, Department of Justice, 2007.

. Domestic extremism lexicon. 29 mar. 2009. Disponível em: <http:// www.fas.org/irp/eprint/lexicon.pdf>. Acesso em: 1 set. 2011.

. Range and racism: skinhead violence on the far righ. 2008a. Disponível

em: <http://info.publicintelligence.net/Skinhead_Rage_and_Racism.pdf>. Acesso em: 1 set. 2011.

White Supremacist recruitment of military personnel since 9/11. 7 july 2008b. Disponível em: <http://cryptome.org/spy-whites.pdf>. Acesso em: 1 set. 2011.

HAINSWORTH, Paul (Ed.). The extreme right in Europe and the USA. New York: St. Martin's Press, 1992.

HOFSTADTER, Richard. The paranoid style in American politics and other essays. Cambridge: Harvard Universiy Press, 1996.

IGNAZI, P.; PERRINEAU, P. L'Extreme Droite en Europe: Marginalité du Neofascisme et Dynamique de l'Extrême Droite Post-industrielle. In: GRUNBERG, Gérard (Org.). Le vote des quinze: les élections Européennes du 13 Juin 1999. Paris: Presses de Sciences Po, 2000. p. 223-242.

IGNAZI, Piero. Extreme rightparties in western Europe. 0xford: Oxford University Press, 2003.

. The intellectual basis of right-wing anti-partytism. European Journal of Political Research, v. 29, n. 3, p. 279-296, 1996.

KALDOR, Mary; GLASIUS, Marlies. Global civil society 2002. 0xford: Oxford University Press, 2002.

KITSCHELT, Herbet; McGANN, Anthony. The radical right in western Europe: a comparative analysis. Michigan: University of Michigan Press, 1995.

MEDEIROS, Sabrina E. Extremismo de direita nos Estados Unidos através da Internet. 2007. Disponível em: <http://www.tempopresente.org/nossa-producao/ 
artigos/39-fluxos-internacionais/2935-extremismo-de-direita-nos-estadosunidos-atraves-da-internet>. Acesso em: 1 set. 2011.

MUDE, Cas. Populism radical right parties in Europe. Cambridge: Cambridge University Press, 2007.

. The war of words defining the extreme right party family. West European Politics, v. 19, n. 2, p. 225-248, 1996.

NORRIS, Pippa. Radical right: voters and parties in the electoral market. Cambridge: Cambridge University Press, 2005.

POGUNTKE, Thomas; SCARROW, Susan. The politics of anti-party sentiment: introduction. European Journal of Political Research, v. 29, p. 257-262, 1996.

PUTNAM, Robert. Bowling alone: the collapse and revival of american community. New York: Simon and Schuster, 2000.

RYDGREN, Jens. Explaining the emergence of radical right-wing populism: the case of Denmark. West European Politics, v. 27, n. 3, p. 474-502, 2004.

. The sociology of the radical right. Annual Review of Sociology, v. 33, p. 241-262, 2007.

SOUTHERN POVERTY LAW CENTER - SPLC. Disponível em: < http://www. splcenter.org/>. Acesso em: 1 set. 2011.

START. National Consortium For the Study of Terrorism and Responses to Terrorism. Background Report: terrorist attacks in New York city. 2010. Disponível em: $<$ http://www.start.umd.edu/start/announcements/announcement.asp?id=185>. Acesso em: 1 set. 2011.

STORMFRONT. Disponível em: < http://www.stormfront.org/forum/> Acesso em: 8 dez. 2011.

TAGGART, Paul. The new populism and the new politics: new protest parties in Sweden in a comparative perspective. Basingstoke: Macmillan, 1996.

. A Touchstone of Dissent: Euroscepticism in Contemporary Western European Party Systems. European Journal of Political Research, v. 33, p. 363388, 1998

TE-SAT. Eu terrorism situation and trend report. EUROPOL. European Policy Office. 2011. Disponível em: <https://www.europol.europa.eu/sites/default/files/ publications/te-sat2011.pdf> . Acesso em: 1 set. 2011.

WALZER, Michael. On toleration. New Haven: Yale University Press, 1997. 